\title{
RESPONSABILIDADE CIVIL DO EMPREGADOR EM CASOS DE ASSÉDIO MORAL NO TRABALHO
}

\author{
EMPLOYER'S CIVIL RESPONSIBILITY IN CASES OF MORAL HARASSMENT AT \\ WORK
}

\author{
Jéssica Alves de Souza ${ }^{1}$ \\ Nádia Karoline Galvão Fontinele ${ }^{2}$ \\ Marcos Nunes Silva Verneck ${ }^{3}$
}

RESUMO: Através deste artigo, pretende-se analisar e identificar o assédio moral no trabalho, no qual busca discutir e debater ideias quanto à responsabilidade civil do empregador nesses casos. Utilizando o método de coleta de dados, bem como pesquisas bibliográficas, será baseado no estudo de doutrinas jurídicas, pesquisas documentais por meio de jurisprudência, o estudo e por fim análise de legislação. Ao final, apresentar métodos de prevenção e reparação aos danos sofridos pelo agente causador.

Palavras-chaves: Assédio Moral. Responsabilidade Civil. Empregador.

ABSTRACT: Through this article, it is intended to analyze and identify bullying at work, in which it seeks to discuss and debate ideas about the civil responsibility of the employer in these cases. Using the method of data collection, as well as bibliographic research, it will be based on the study of legal doctrines, documentary research through jurisprudence, the study and finally analysis of legislation. At the end, present methods of preventing and repairing the damage suffered by the causative agent.

Keywords: Moral Harassment. Civil Liability. Employer.

\section{INTRODUÇÃO}

A reflexão acerca da responsabilidade civil do empregador em casos de assédio moral no trabalho, visa proporcionar conteúdos educativos e pedagógicos voltados para as pessoas desprovidas de conhecimento sobre assédio moral no trabalho.

Tendo em vista, que muitos não sabem o que caracteriza ou não, o assédio moral no trabalho e quais medidas cabíveis tomar. O presente estudo tem o intuito de acrescentar e explanar sobre o referido assunto, conceituando assédio moral, configuração e suas espécies, bem como, a relação jurídica do empregador quanto à responsabilidade civil.

I Acadêmica de Bacharelado em Direito da Faculdade São Lucas. E-mail: Jessicatorrees_@hotmail.com. 2 Acadêmica de Bacharelado em Direito da Faculdade São Lucas. E-mail:nkfontineleg2@gmail.com.

3 Professor Especialista da Faculdade São Lucas. E-mail: marcos.verneck@saolucas.edu.br 
O assédio moral no trabalho consiste em uma violência psicológica e mental, com o intuito de humilhar o colaborador, querendo o entristecer e o amedrontar causando abalos psíquicos, muitas vezes não sabendo diferenciar uma crítica rotineira de um assédio moral, frisa-se ainda que muitos empregadores se esquivam das suas responsabilidades.

Assim, em que pese à dura realidade do crescimento do assédio moral no trabalho na sociedade moderna, é reconfortante observar que paralelamente crescem também os mecanismos de proteção aos colaboradores.

\section{Conceito de Assédio Moral}

A origem desse revés vem do tempo da escravidão como fardo cultural e está diretamente ligado ao desenvolvimento da sociedade e o avanço do sistema capitalista, no qual sucederam às relações de trabalho e suas hierarquias. Recentemente o assunto ganhou repercussão na área jurídica, em sua maioria em ocorrências nas relações de trabalho (JUS, 20II).

Assédio moral ou violência moral no trabalho não é um fenômeno novo. Pode-se dizer que ele é tão antigo quanto o trabalho. Tal fenômeno é resultado de um estudo científico desenvolvido no âmbito da psicologia e medicina, através de pesquisadores em psicologia do trabalho. De nacionalidade alemã Heinz Leymann desenvolveu suas pesquisas sobre assédio na Suécia o precursor nesta matéria, após identificar o fenômeno o nominou de "mobbing" como sendo:

O fenômeno no qual uma pessoa ou grupo de pessoas exerce violência psicológica extrema, de forma sistemática e recorrente e durante um tempo prolongado - por mais de seis meses e que os ataques se repitam numa frequência média de duas vezes na semana - sobre outra pessoa no local de trabalho, com a finalidade de destruir as redes de comunicação da vítima ou vítimas, destruir sua reputação, perturbar a execução de seu trabalho e conseguir finalmente que essa pessoa ou pessoas acabe abandonando o local de trabalho (LEYMANN, I990, p. I2I).

Roberto Zanetti conceitua assédio moral no trabalho como sendo:

O assédio moral se define pela intenção de uma ou mais pessoas praticarem, por ação ou deixarem de praticar por omissão, de forma reiterada ou sistemática, atos abusivos ou hostis, de forma expressa ou não, contra uma ou mais pessoas, no ambiente de trabalho, durante a jornada de trabalho e no exercício de suas funções, principalmente por superiores hierárquicos, após, colegas ou mesmo por colegas e superiores hierárquicos e em menor proporção, entre outros, por inferiores hierárquicos e clientes, durante certo período de tempo e com certa frequência, os quais venham atingir a saúde do trabalhador, após o responsável ter sido comunicado a parar com eles e não ter parado. (ZANETTI, 2009, p. 27). 
Assédio é o termo utilizado para designar toda conduta que cause constrangimento psicológico ou físico à pessoa. Assédio moral é um tipo de assédio, e não ocorre somente no ambiente do trabalho, ele pode estar presente nas relações de cônjuges, ambiente familiar, nas escolas, etc. Entretanto, o presente artigo versará sobre o assédio moral no ambiente de trabalho que se caracteriza por toda conduta abusiva de natureza psicológica, onde o trabalhador é exposto a situações humilhantes e constrangedoras que atentam contra a dignidade psíquica de forma repetida e prolongada, provocando abalo emocional, ferindo sua dignidade, sua personalidade e visando prejudicar o empregado no exercício de suas funções (JUS, 20II).

\section{I Configuração do Assédio Moral}

De acordo com o primeiro requisito, o da conduta abusiva no ambiente do trabalho, não é possível uma definição rígida. Isto porque "sua definição é aberta e está abertura facilita excessos, os quais devem ser reprimidos quando seus elementos não estiverem presentes” (ZANETTI, 2009, p.28).

O segundo requisito é o da repetição, que se configura assédio moral através de atos que desestabilizam a vítima psicologicamente e que sejam adotadas de forma padronizada se prolongando no tempo, "a duração média dos ataques tem que ser de 6 (seis meses), segundo estudo estatístico realizado por Heinz Leymann. Assim como na frequência, esta é a regra, havendo exceções (JURISWAY, 20II).

O terceiro requisito se dá pela ameaça à permanência do indivíduo no trabalho ou a sua integridade física e psíquica no ambiente laboral. $\mathrm{O}$ objetivo do assediador, de forma consciente ou não, é eliminar o indivíduo da organização (JURISWAY, 20II).

É importante ser analisado cada ato, ataques aparentemente inofensivos com o passar do tempo acabam por afetar a vítima, criando confusão quanto ao ambiente de trabalho hostil, chegando a ser insuportável a convivência profissional, afetando a sua autoestima e satisfação no trabalho (JURISWAY, 2oII). 
2.2 Espécies de Assédio Moral

2.2.I Assédio Moral Vertical Descendente

Esta forma de assédio é a mais frequente, ela acontece através das relações hierárquicas nas organizações laborais, ou seja, procedimentos abusivos praticados pelo próprio empregador ou um de seus superiores para com seu subordinado (CARVALHO, 2008).

No que diz respeito à dignidade da pessoa humana do trabalhador a prática do assédio moral pelo empregador ou superior hierárquico ocasiona descumprimento da obrigação contratual por parte do empregador. Entretanto, esta subordinação não dá ao empregado o direito de humilhar e maltratar o trabalhador a fim de alcançar seus objetivos (CARVALHO, 2008).

\subsubsection{Assédio Moral Vertical Ascendente}

Provém do assédio moral praticado por parte de um ou de vários subordinados contra seu superior, em sua maioria praticado por vários agressores ao mesmo tempo (JURISWAY, 20II).

Esta forma de assédio pode ocorrer por haver inexperiência ou até mesmo insegurança do superior hierárquico, no qual não consegue desenvolver a gestão laboral quanto aos subordinados. Através de pesquisa realizada na França, Hirigoyen (2005) demonstrou que $58 \%$ dos casos de assédio moral vêm da hierarquia, ou seja, são "assédios verticais descendentes". Em 29\% dos casos, eles decorrem de colegas e chefias imediatas e I2\% constituem casos de assédio de colegas. Apenas I\% dos assédios são provenientes de subordinados (OLIVEIRA E VENÂNCIO, 2012).

\subsection{Assédio Moral Horizontal}

No assédio horizontal, a prática se produz por colegas de trabalho de mesmo nível hierárquico da vítima, por meio de brincadeiras indelicadas, maliciosas, gestos obscenos, desprezo entre outros. Geralmente em razão de competitividade salarial e disputa em promoções para cargos superiores (OLIVEIRA E VENÂNCIO, 20I2). 
2.4 Assédio Moral Misto

O assédio moral será misto, quando praticado pelo superior hierárquico juntamente com seus colegas de trabalho, um assédio moral horizontal frequente, sem interferência da hierarquia, que se torna cúmplice resultando no assédio moral misto. São raros os casos de assédio moral horizontal que não são seguidos também pelo assédio vertical descendente, que se manifesta pela omissão da chefia ou do superior hierárquico à conduta degradante imposta pelo agressor (JURISWAY, 20II).

\section{Aspecto Histórico da Responsabilidade}

Esse termo chamado "responsabilidade" é muito comum e muito usado em diversas áreas da ciência, nas relações jurídicas e naturais. Pois se alguém prática determinado ato que afete ou fira a integridade de um indivíduo, essa pessoa deverá arcar com os danos causados (ZANETTI, 2009).

Vejamos o seguinte conceito de responsabilidade:

$$
\begin{aligned}
& \text { No direito civil, o tema da responsabilidade integra o ramo do direito obrigacional, } \\
& \text { relativo ao dever, segundo o qual a conduta humana está vinculada ao seu fim, } \\
& \text { econômico ou social, e, na eventualidade do descumprimento da obrigação, surge, } \\
& \text { então, o dever de compensar o dano causado (PENAFIEL, 2ol3). }
\end{aligned}
$$

Nos tempos antigos, por meados do século XVIII a.C., na Mesopotâmia, quando alguém praticava algum ato injusto ou indevido, a exigência era que fosse retaliado da mesma forma que causou o sofrimento ao outro, esta conduta era nomeada por uma expressão chamada "olho por olho, dente por dente" que integrava parte do Código de Hamurabi (PEBMED, 2018).

Assim, como a natureza evolui, o ser humano e suas convicções se transformam e progridem, adotaram novas normas que sujeitam o causador do dano a compensar a vítima, foi desta forma que surgiu a Lei das XII Tábuas. A Lei Aquilia é quem surge com princípios que regulamentam a retratação dos danos causados, porém, necessita provar a culpa do agente, pois ela é um requisito para reparação do dano causado (PEBMED, 2018).

No Direito Francês foi estabelecido de forma mais profunda a responsabilidade civil, bem como, há uma distinção entre a sanção e a reparação, pois há para a exigência que o causador será responsabilizado, deve haver a comparação se o dano causado é resultado da culpa do agente. Vale destacar que o Código de Napoleão foi o marco inicial da teoria que 
regulamenta a responsabilidade civil nos ordenamentos jurídicos modernos (PEBMED, 2018).

3.I Responsabilidade do Empregador

Após a identificação do assédio moral, é necessário que alguém seja responsabilizado pelos danos causados aos colaboradores, tendo em vista, que isso causa grandes sequelas psicológicas e consequentemente físicas (ZANETTI, 2009).

Depois da identificação do assédio, deverá começar a procurar o responsável nessas situações e em decorrência disso, o empregador é selecionado a ser o responsável na reparação dos danos causados, pois assim, como o Estado responde por danos causados em decorrência de um acidente de trânsito, quando o agente causador do dano estiver utilizando veículos da administração pública, por mais que o Estado não teve parcela de culpa, é o Estado quem será responsabilizado em ressarcir eventuais prejuízos causados à vítima (RONDELLI, 2008).

Vejamos o seguinte julgado do egrégio Tribunal Regional do Trabalho, acerca de assédio moral horizontal:

\begin{abstract}
ASSÉDIO MORAL HORIZONTAL. Ainda que não haja participação direta das chefias empresariais no assédio moral, preservando-se o assédio como tipicamente horizontal (colegas versus colegas), não desaparece a responsabilidade do empregador pela lesão causada, por ser inerente ao poder empregatício dirigir, fiscalizar e punir os participantes da organização empresarial dentro do estabelecimento. (TRT-4 - RORSUM: 0021876742019504027I, Data de Julgamento: 20/o6/2020, 3 $3^{\text {a }}$ Turma) (Grifo nosso)
\end{abstract}

Do mesmo modo é aplicado no assédio moral, por mais que não seja o empregador, o real causador do dano (também conhecido como assédio moral horizontal), o empregador é o responsável sim em casos de assédio moral no trabalho (RONDELLI, 2008).

No setor público, por não haver demissão direta ou imotivada, é comum que haja assédio moral, devido as hierarquias, burocracias, preconceitos e dentre outros. E nesses casos, o responsável pelos atos praticados por terceiros e seus agentes públicos são as pessoas jurídicas de direito público e privado, conforme artigo $37, \S^{\circ}$ - da CF/88 (JUS.COM.BR, 2019).

Art. 37 (...)

§ 6 o As pessoas jurídicas de direito público e as de direito privado prestadoras de serviços públicos responderão pelos danos que seus agentes, nessa qualidade, causarem a terceiros, assegurado o direito de regresso contra o responsável nos casos de dolo ou culpa. 
Vejamos o seguinte julgado, a respeito da responsabilidade do estado e do agente causador do dano:

\begin{abstract}
ADMINISTRATIVO E CIVIL. AÇÃO DE INDENIZAÇÃO. RESPONSABILIDADE OBJETIVA DO ESTADO. ASSÉDIO MORAL NO LOCAL DE TRABALHO. COMPROVAÇÃO. CONJUNTO PROBATÓRIO HARMÔNICO. DANO MORAL CONFIGURADO. QUANTUM DEBEATUR ARBITRADO COM ACERTO. RECURSO CONHECIDO E DESPROVIDO. SENTENÇA MANTIDA. I) A responsabilidade civil do Estado é, de regra, objetiva (art. 37, § 6ㅇ, da CF) e, como tal, prescinde da demonstração da culpa em sentido amplo do agente estatal. Dessa maneira, tal responsabilidade civil nasce sempre que evidenciada a ocorrência de uma ação administrativa e um dano, estes ligados por um nexo de causalidade, salvo se comprovado motivo de força maior ou a culpa exclusiva da vítima. 2) $\mathrm{Na}$ hipótese, o conjunto probatório revela que a Autora sofreu tratamento hostil no cotidiano do trabalho, remoção imotivada e declarações públicas ofensivas de superior hierárquico, diretora e diretora-adjunta do Núcleo de Atividades em Altas Habilidades - Superdotação - NAAH/S, situações que violam a dignidade da pessoa, configurando o assédio moral. 3) Ficou evidenciando, ainda, que o assédio tinha relação com o fato da Autora apoiar a gestão passada, que é diversa da atual, sendo o motivo inquestionavelmente inidôneo a justificar o ato ilícito perpetrado. Além disso, esses fatos provocaram constrangimento físico e psíquico pois as testemunhas afirmaram que a Autora, por várias vezes, atingiu o choro no seu local de trabalho diante do tratamento hostil a ela dispensado. 4) Cabalmente configurado o assédio moral, o arbitramento de $\mathrm{R} \$$ 5.00o,oo (cinco mil reais) a título de indenização harmoniza-se com o princípio da proporcionalidade e da razoabilidade e, ainda a vedação do enriquecimento, sem causa do servidor. 5) Recurso conhecido e improvido. Sentença mantida. (TJ-AP - RI: 0003809202012803000I AP, Relator: SUELI PEREIRA PINI, Data de Julgamento: iI/o6/2013, TURMA RECURSAL DOS JUIZADOS ESPECIAIS) (Grifei).
\end{abstract}

Conforme artigo e julgado demonstrados, nota-se que a responsabilidade do Estado é objetiva e a responsabilidade civil do agente causador do dano é subjetiva. Assim, como no meio privativo entre as empresas, é necessário a comprovação do nexo de causalidade com o dano, na administração pública ocorre da mesma forma, ou seja, o Estado responde de forma objetiva, de modo que não há importância se houve o cuidado para evitar que esse dano ocorresse e os servidores públicos só respondem se for constatado que houve dolo ou culpa, que no caso deles é a responsabilidade subjetiva (JUS.COM.BR, 2019).

3.2 Responsabilidade Civil Objetiva e Subjetiva

A responsabilidade civil do empregador se difere em objetiva e subjetiva, sendo necessários em alguns casos comprovar a culpa do indivíduo que causou o dano. $\mathrm{Na}$ responsabilidade civil objetiva, visa a comprovação do dano causado, ou seja, é necessário a 
demonstração do fato que deu ao acidente e/ou dano, seguido de nexo causal, é preciso que seja demonstrado toda cadeia sucessória para exigir a compensação do dano, contudo, não há necessidade de comprovar se o agente tem culpa ou dolo (SOARES, p.8).

$\mathrm{Na}$ responsabilidade civil subjetiva tem como requisito primordial a comprovação da culpa, enquanto na objetiva é totalmente o oposto, não sendo necessário a comprovação da culpa (RONDELLI, 2008).

O artigo I86 do Código Civil, dispõe a respeito de responsabilidade civil subjetiva, "aquele que, por ação ou omissão voluntária, negligência ou imprudência, violar direito e causar dano a outrem, ainda que exclusivamente moral, comete ato ilícito" (BRASIL, 2002, artigo I86).

Sebastião Geraldo de Oliveira preceitua que "a responsabilidade é subjetiva quando o dever de indenizar surgir em razão do comportamento do sujeito que causa danos a terceiros, por dolo ou culpa".

$\mathrm{Na}$ responsabilidade civil objetiva visa a proteção do dano causado com fundamento no risco da atividade desenvolvida e na responsabilidade civil subjetiva ela estipula que há necessidade de comprovação do ato ilícito, obrigando o agente a reparar o dano causado (RONDELLI, 2008).

3.3 Medidas de Reparação dos danos

As consequências provocadas pelo assédio moral são inúmeras, pois atingem sua dignidade humana, personalidade moral, profissional, social, familiar, integridade física e psíquica do assediado, as consequências são desastrosas que não há como imaginar a intensidade do abalo e sofrimento psicológico (RONDELLI, 2008).

Sendo assim, depois de provado os danos sofridos pelo agente causador com o nexo de causalidade, o magistrado irá fixar o montante da indenização e verificar se haverá danos materiais cumulados. O ressarcimento dos danos morais e materiais tem fulcro no artigo 186 do Código Civil e 927 da CF/88 (RONDELLI, 2008).

Para fixação dos danos morais, depois de analisar as provas, o juiz vai avaliar qual o valor da indenização e se há necessidade de arbitrar os lucros cessantes e pensão. Não há como recuperar o dano causado e suas consequências, o dano moral tem o intuito de minimizar ou acalentar as consequências causadas pelo assédio sendo um meio de sanção de 
caráter punitivo e pedagógico, com o intuito de dirimir futuros assédios morais (RONDELLI, 2008).

Para Savatier, um grande jurista francês dano moral é:

\begin{abstract}
Qualquer sofrimento humano que não é causado por uma perda pecuniária, e abrange todo atentado à reputação da vítima, à sua autoridade legítima, ao seu pudor, à sua segurança e tranquilidade, ao seu amor próprio estético, à integridade de sua inteligência, a suas afeições, etc." (Traité de La Responsabilité Civile, vol.II, $\mathrm{n}^{\mathrm{o}}$ 525, in Caio Mario da Silva Pereira, Responsabilidade Civil, Editora Forense, RJ, 1989).
\end{abstract}

O dano material cabe às despesas médicas, farmacêuticas e se houve lucros cessantes, a fixação do quantum indenizatório será calculado conforme os gastos de cada despesa, esse costuma ser exato aos valores gastos, pois tem que demonstrar com notas fiscais os valores das despesas (RONDELLI, 2008).

Vejamos o seguinte julgado:

BANCÁRIO. ASSÉDIO MORAL. DANOS MORAIS E MATERIAIS DESPESAS MÉDICAS. INDENIZAÇÃO. VALOR. Demonstrado o abuso do poder diretivo do empregador, na forma do art. 187 do Código Civil, remanesce incólume a sentença condenatória de reparação por danos morais. Em tal cenário, é devida indenização correspondente, a qual deve ser proporcional ao dano sofrido. Outrossim, comprovadas as despesas médicas, cabível o ressarcimento. OBTENÇÃO DE CERTIFICAÇÃO. Admitindo o empregador tratar-se o AMBIMA de certificação obrigatória, é devido o ressarcimento para a sua obtenção. HONORÁRIOS PERICIAIS. VALOR. Não merecem decote honorários periciais arbitrados em montante razoável e compatível com a complexidade da perícia. (TRT-ro oooo2707720155100007 DF, Data de Julgamento: 29/03/2017, Data de Publicação: 07/04/2017) (Grifo nosso).

Sendo assim, deverá a vítima juntar aos autos toda a comprovação e pedir indenização por ressarcimento de danos materiais, pelas despesas custeadas e a indenização como forma de amenizar o dano sofrido, por mais que não haja que possa compensar qualquer dor sofrida, somente ameniza o dano causado (RONDELLI, 2008).

\title{
4 RESPONSABILIDADE CIVIL DO EMPREGADOR EM CASOS DE ASSÉDIO MORAL NO TRABALHO
}

O ordenamento jurídico brasileiro preceitua que ao causar dano a alguém, o agente causador do dano deverá ressarcir conforme a extensão do dano. $\mathrm{O}$ artigo 927 do Código Civil estabelece quanto a obrigação de repará-lo (ÂMBITO JURÍDICO, 2017).

Vejamos o seguinte artigo, elencado no CC: 
Art. 927. Aquele que, por ato ilícito (art. I86 e 187), causar dano a outrem, fica obrigado a repará-lo.

Parágrafo único. Haverá obrigação de reparar o dano, independentemente de culpa, nos casos especificados em lei, ou quando a atividade normalmente desenvolvida pelo autor do dano implicar, por sua natureza, risco para os direitos de outrem.

A obrigação de reparar à vítima em casos de assédio moral no meio laboral, é reconhecida como responsabilidade objetiva, no qual a empresa ou empregador responde de forma solidária juntamente com os colaboradores, pois o empregador também é responsabilizado pelos danos causados através terceiros (ÂMBITO JURÍDICO, 2017).

Senão, vejamos a seguir o seguinte julgado do Egrégio Tribunal de Justiça, no qual aduz sobre a responsabilidade objetiva em casos de assédio moral:

E M E N T A - APELAÇÃO CÍVEL. AÇÃO DE INDENIZAÇÃO POR DANOS MORAIS - ASSÉDIO MORAL - RESPONSABILIDADE OBJETIVA - DANO NÃO COMPROVADO. RECURSO PROVIDO. O ente estadual possui responsabilidade objetiva pelos danos praticados a terceiros, à luz da Teoria do Risco Administrativo, consagrada pela Constituição Federal no art. 37 , \& 6\%. O dever de indenizar impõe o reconhecimento do dano em razão do comportamento do preposto do Estado, que não se verifica na espécie. (TJ-MS AC: o0681030320108120001 MS o068103-03.2010.8.12.00or, Relator: Des. Odemilson Roberto Castro Fassa, Data de Julgamento: 08/11/2018, 4⿳㇒ Câmara Cível, Data de Publicação: II/II/2018) (Grifo nosso)

$\mathrm{Na}$ responsabilidade subjetiva, decorre da comprovação de culpa do agente causador do dano, a empresa será obrigada a reparar o dano causado pelos seus funcionários a outrem, de forma que independe se houver culpa, dolo ou omissão (ÂMBITO JURÍDICO, 2017).

Vejamos a seguir, o julgado:

APELAÇÃO CÍVEL. SERVIDOR PÚBLICO. MUNICÍPIO DE CACHOEIRINHA. ENFERMEIRA. DANO MORAL. RESPONSABILIDADE SUBJETIVA. ASSÉDIO MORAL. AUSÊNCIA DE DEMONSTRAÇÃO. ÔNUS DA PROVA. ART. 373, I, DO CPC/I5.I. Consoante entendimento doutrinário e jurisprudencial, a responsabilidade do ente público aos seus servidores é subjetiva, o que implica a perquirição dos seus elementos configuradores, quais sejam: o dano, o nexo de causalidade entre a ação e o resultado danoso, bem como a conduta culposa do agente causador. 2. $\mathrm{Na}$ espécie, tratando-se de dano não presumível, cabia à demandante especificar e, mais do que isso, comprovar o alegado assédio moral sofrido, a teor do art. 373 , I, do $\mathrm{CPC} / 15$, o que não se depreende da análise dos autos .3. Sentença de improcedência na origem. APELAÇÃO DESPROVIDA. (TJ-RS - AC: 70071677876 RS, Relator: Antônio Vinícius Amaro da Silveira, Data de Julgamento: 24/o7/2019, Quarta Câmara Cível, Data de Publicação: o6/o8/2019) (Grifo nosso).

Portanto, mesmo que o empregador não foi o causador do dano ele ainda assim será condenado a reparar a vítima com uma indenização, como forma de dirimir ou amenizar o 
sofrimento, bem como terá caráter-punitivo pedagógico como uma forma de evitar a repetição do assédio moral (ÂMBITO JURÍDICO, 2017).

\section{CONSIDERAÇÕES FINAIS}

Ao decorrer do trabalho conclui-se que o assédio moral é a exposição repetitiva que se prolongam no tempo a condutas abusivas, humilhantes que atentam contra a dignidade da pessoa humana e venham a degradar a saúde física e psíquica do trabalhador no ambiente laboral.

$\mathrm{Na}$ atualidade se tornou comum a incidência do assédio moral, vindo a ser considerada uma consequência natural de acordo com a gestão de pessoas e organização que as empresas ou algumas profissões adotam.

Os efeitos nocivos na vida do trabalhador, trazem consequências em suas relações interpessoais e sociais. Muitas vezes irreversíveis, a vítima poderá desenvolver sequelas com distúrbios permanentes, em alguns casos mais severos, até mesmo atentar contra a própria vida.

A melhor forma de combater o assédio moral no trabalho é praticando a prevenção, de forma a conscientizar todos os indivíduos (empregados/empregadores), sobre o assunto e excluir do meio ambiente laboral qualquer espécie de conduta abusiva que venha a ferir a dignidade da pessoa humana.

É necessário ter consciência que a prática de assédio moral no ambiente laboral acarreta danos à vítima e também a própria organização empresarial a qual é empregado.

A responsabilização dos agressores no assédio moral deverá ser efetiva, de modo a inibir a continuidade das condutas lesivas e a desestimular sua prática aos demais.

Tal responsabilização do empregador dar-se não somente na esfera trabalhista, como também na esfera cível (indenização pelo dano), e, até mesmo na esfera penal (tipificando novas condutas a fim de coibir as práticas abusivas), em busca de um ambiente laboral saudável proporcionando qualidade de vida aos trabalhadores.

Não há dúvidas de que abusos em ambientes laborais pela prática de assédio moral representa ataque direto à dignidade da pessoa humana. É fato que, uma vez o homem desprovido de sua dignidade, fundamento da Democracia brasileira dotado de superioridade 
hierárquica, nada mais lhe resta, tornando-se ineficaz todas as demais garantias asseguradas pelo ordenamento jurídico.

\section{REFERÊNCIAS BIBLIOGRÁFICAS}

ANTUNES, Carina Raquel de Oliveira de Souza. Assédio moral no ambiente do trabalho: Conceituação jurídica, características e responsabilidades da empresa. Âmbito Jurídico. or de agosto de 2017. Acesso em: 04 de novembro de 2021. Disponível em: < https://ambitojuridico.com.br/edicoes/revista-I63/assedio-moral-no-ambiente-dotrabalho-conceituacao-juridica-caracteristicas-e-responsabilidades-da-empresa/ >

AUTHOR, Guest. Quais são as responsabilidades civis do empregador? CEZZANE. 30 de março de 2017. Acesso em: o8 de novembro de 2021. Disponível em: <https://cezannehr.com/pt/hr-blog/2017/o3/quais-sao-responsabilidades-civisempregador/>

BARBOSA, Tiago Henrique Gomes da Silva. Assédio Moral No Ambiente do Trabalho. Jurisway. 20 de dezembro de 2011. Acesso em 8 de novembro de 2021. Disponível em: 〈https://www.jurisway.org.br/v2/dhall.asp?id_dh=698o>

BRASIL. Constituição (1988). Constituição da República Federativa do Brasil. Brasília, DF: Centro Gráfico, 1988.

BRASIL. Lei no 10.406 , de ro de janeiro de 2002. Institui o Código Civil. Diário Oficial da União: seção I, Brasília, DF, ano I39, n. 8, p. ı-74, II jan. 2002.

CARVALHO, Nordson Gonçalves. Assédio Moral e Diginidade da Pessoa Humana do Trabalhador. Dissertação (Mestrado em Direito) - Centro Universitário FIEO. Osasco. 2008. Acesso em 02 de dezembro de 2021. Disponível em: 〈http://www.unifieo.br/files/pdf/dissertacao_nordson.pdf〉

CASTRO, Anne Beatriz Mota De. A responsabilidade civil do empregador perante o assédio moral nas relações de trabalho. Conteúdo Jurídico. i7 de novembro de 2017. Acesso em: 07 de novembro de 2021. Disponível em: <https://conteudojuridico.com.br/consulta/Artigos/51025/a-responsabilidade-civil-doempregador-perante-o-assedio-moral-nas-relacoes-de-trabalho>

FILHO, Aloizio Apoliano Cardozo. Conceito, terminologia e elementos caracterizadores do assédio moral nas relações de trabalho. Revista Jus Navigandi. Teresina: ano I6, n. 2957, 6 ago. 20II. Disponível em: <https://jus.com.br/artigos/197io/conceito-terminologia-eelementos-caracterizadores-do-assedio-moral-nas-relacoes-de-trabalho>

LEYMANN, Heinz (2000a), "Mobbing”. Acesso em 5 de novembro de 2021. Disponivel em: 〈http://www.leymann.se/English/r210oE.HTM> 
NIGRE, André Luis. Síntese de uma visão histórica da responsabilidade civil. PEBMED. 24 de março de 2018. Acesso em: 07 de novembro de 2021. Disponível em: 〈https://pebmed.com.br/sintese-de-uma-visao-historica-da-responsabilidade-civil/〉

OLIVEIRA, I.; VENÂNCIO, V. F. As contribuições de autores sobre assédio moral nas organizações públicas. Revista Magistro. Rio de Janeiro: Unigranrio. Vol. I Num. I. 2012. Acesso em or de dezembro de 2021. Disponível em: $\langle$ http://publicacoes.unigranrio.edu.br/index.php/magistro/article/viewFile/ı666/818〉

PENAFIEL, Fernando. Evolução histórica e pressupostos da responsabilidade civil. Âmbito Jurídico. or de abril de 2013. Acesso em: o7 de novembro de 2021. Disponível em: 〈https://ambitojuridico.com.br/cadernos/direito-civil/evolucao-historica-e-pressupostosda-responsabilidade-civil/>

RODRIGUES, Clarissa Fernanda. Responsabilidade do estado por assédio moral de servidores. JUS.COM.BR. Setembro de 2019. Acesso em: o6 de dezembro de 2021. Disponível em: < https://jus.com.br/artigos/767II/responsabilidade-do-estado-por-assediomoral-de-servidores $>$

RONDELLI, Cristiane Montenegro. Assédio Moral na Relação de Emprego e Responsabilidade Civil do Empregador. Tese (Mestrado em Direito). PONTIFÍCIA UNIVERSIDADE CATÓLICA DE SÃO PAULO PUC-SP. São Paulo. 2008.

SOARES, Fernanda de Carvalho. RESPONSABILIDADE CIVIL EM FACE DO ASSÉDIO MORAL NO TRABALHO. PublicaDireito (Artigo). Acesso em: o8 de novembro de 2021. Disponível em: $\left\langle\right.$ http://www.publicadireito.com.br/artigos/?cod=05a99coob975ffi5\#: :text=O\%20ass\% $\mathrm{C}_{3}$ \%A9dio\%20moral\%20enseja\%20a,atos\%2opraticados\%20por\%20seus\%2oempregados >

SOUSA, Patrícia. SANTOS, Francisco. COSTA, Maria. Assédio Moral no Ambiente Laboral: O Papel do Estado Brasileiro diante do assédio moral praticado no ambiente laboral das organizações privadas no Brasil à luz da dignidade da pessoa humana. Âmbito Jurídico. or de junho de 2020. Acesso em: o6 de dezembro de 2021. Disponível em: < https://ambitojuridico.com.br/cadernos/direito-constitucional/assedio-moral-noambiente-laboral-o-papel-do-estado-brasileiro-diante-do-assedio-moral-praticado-noambiente-laboral-das-organizacoes-privadas-no-brasil-a-luz-da-dignidade-da-pessoahumana/>

ZANETTI, Robson. Assédio Moral no Trabalho. Ebook. 2004. Acesso em 8 de novembro de 2021. Disponível em: 〈https://bdjur.stj.jus.br/jspui/bitstream/20II/r8893/Livro_Ass\%c3\%agdio_Moral.pdf〉 